\title{
Selective endothelin A-receptor blockade attenuates coronary microvascular dysfunction after coronary stenting in patients with type 2 diabetes
}

This article was published in the following Dove Press journal:

Vascular Health and Risk Management

27 October 2009

Number of times this article has been viewed

Nikolaos Östlund Papadogeorgos

Mattias Bengtsson

Majid Kalani

Karolinska Institute, Department of Clinical Sciences, Department of Cardiology, Danderyd Hospital, Stockholm, Sweden
Correspondence: Majid Kalani

Dept of Cardiology, Danderyd Hospital,

SE-182 88 Stockholm, Sweden

Tel +468 6555000

Email majid.kalani@ds.se
Background: Endothelin-1 may be involved in the development of diabetic microangiopathy. We studied the effect of endothelin-1 blockade on myocardial microcirculation during coronary stenting.

Patients and methods: Patients with type 2 diabetes and stable coronary artery disease undergoing elective percutaneous coronary intervention (PCI) were randomized to bolus dose of $500 \mathrm{mg}$ bosentan $(\mathrm{n}=4)$, a dual endothelin receptor blocker, or intracoronary administration of $0.03 \mathrm{mmol} \mathrm{BQ123}(\mathrm{n}=6)$, a selective endothelin A-receptor blocker, or placebo $(\mathrm{n}=5)$, respectively. Coronary flow reserve (CFR) was measured immediately post-PCI. CFR was also measured in five nondiabetic controls post-coronary stenting.

Results: Patients in the placebo group had $(P<0.05)$ lower values of CFR $(2.3 \pm 1.2)$ as compared to those who received endothelin blockade $(\mathrm{n}=10 ; 3.1 \pm 0.7)$ and nondiabetic controls (4.9 \pm 2.3$)$. Patients who received BQ123 showed significantly higher CFR $(3.3 \pm 0.5 ; P<0.05)$ as compared to those on placebo. Nondiabetic patients had significantly higher CFR as compared to patients with diabetes ( $4.9 \pm 2.3$ and $2.8 \pm 1.0$, respectively; $P<0.05)$.

Conclusion: Coronary microvascular dysfunction is present during coronary stenting in patients with type 2 diabetes and may be reversed by selective endothelin A-receptor blockade. Targeting endothelin system may be of importance in protecting the myocardium against ischemic events during elective PCI in type 2 diabetic patients.

Keywords: coronary flow reserve, diabetes, endothelin-1, coronary artery disease, coronary angioplasty

\section{Background}

Endothelial dysfunction, characterized by an imbalance between endothelium-derived vasodilator and vasoconstrictor substances, plays an important role in the pathogenesis of vascular complications in diabetes, including microangiopathy. ${ }^{1,2}$ One important feature of endothelial dysfunction is an increased production and biological activity of the potent vasoconstrictor and proinflammatory peptide endothelin-1 (ET-1), which has been suggested to be involved in the development of cardiovascular disease, including diabetic microangiopathy. ${ }^{3}$ Activation of endothelin A-receptor $\left(\mathrm{ET}_{\mathrm{A}}\right)$ contributes to coronary constrictor tone and peripheral and coronary endothelial dysfunction. ${ }^{4,5}$

Elevated levels of ET-1 are found in patients with type 2 diabetes. ${ }^{6,7}$ Selective $^{E_{1}}$ receptor blockade by $\mathrm{BQ} 123$ markedly increases the nutritive skin microcirculation in patients with type 2 diabetes and microangiopathy. ${ }^{8}$ These results suggest that ET-1, through activation of the $\mathrm{ET}_{\mathrm{A}}$ receptor, is of importance for the regulation of the peripheral microcirculation in diabetic patients with microangiopathy. 
An impaired coronary flow reserve (CFR) has been demonstrated in patients with metabolic syndrome and type 2 diabetes without clinical evidence of coronary artery disease. ${ }^{9,10}$ Percutaneous coronary intervention (PCI) with balloon angioplasty and coronary stenting causes arterial injury, resulting in platelet activation, vasoconstrictor release and abnormalities in endothelial-dependent vasodilatation, which in some patients might lead to adverse effects on the microvascular function. ${ }^{11-13}$ The aim of the present study was to evaluate CFR and to determine the effect of dual and selective $\mathrm{ET}_{\mathrm{A}}$ blockade, respectively, on CFR in patients with type 2 diabetes undergoing elective coronary stenting.

\section{Material and methods}

\section{Patient population}

Twenty patients, 15 with type 2 diabetes and five nondiabetic patients undergoing nonacute PCI were eligible for the study. The patients were admitted for elective PCI because of stable one vessel coronary artery disease. Exclusion criteria included previous myocardial infarction in the territory of the study artery, congestive heart failure and previous coronary artery bypass grafting. Informed consent was obtained from all patients. The study was approved by the local human ethics committee of the Karolinska Institute.

\section{Methods}

All patients were treated with aspirin, statins and betablockers. Patients with diabetes and three controls were treated with angiotensin-converting enzyme inhibitor. All patients received a loading dose of $600 \mathrm{mg}$ clopidogrel 12 hours prior to PCI, followed by $75 \mathrm{mg}$ on the procedure day. Patients were asked to refrain from coffee for at least 12 hours before PCI. Patients with diabetes were randomized to receive either dual ET-1 receptor blocker bosentan (Group A; n = 4) $\left(\right.$ Tracleer $^{\circledR}$, Actelion Pharmaceuticals, Allschwil, Switzerland) or the selective $\mathrm{ET}_{\mathrm{A}}$ blocker BQ123 (Group B; $\mathrm{n}=6$ ) (Clinalfa, Läufelfingen, Switzerland) or placebo tablets (Group C; $\mathrm{n}=5$ ). Patients in Group A received a bolus dose of $500 \mathrm{mg}$ bosentan three hours prior to PCI. In Group B, a total dose of $0.03 \mathrm{mmol}(9 \mathrm{~mL}) \mathrm{BQ} 123$ was injected intracoronary during the PCI procedure; $0.01 \mathrm{mmol}$ before inflation of the predilation balloon, $0.01 \mathrm{mmol}$ after balloon deflation, and $0.01 \mathrm{mmol}$ after stenting. Group $\mathrm{C}$ received placebo tablets three hours prior to PCI. The doses of BQ123 and bosentan, respectively, were based on previous studies on peripheral vascular function. ${ }^{14,15} \mathrm{CFR}$ and fractional flow reserve (FFR) were measured post-PCI in all patients including five nondiabetic controls.

\section{$\mathrm{PCl}$ with coronary stenting}

All patients underwent one vessel PCI with coronary stenting with either drug-eluting stents or bare metal stents via 6-French guiding catheters. All patients received the lowmolecular-weight heparin enoxaparin $(0.5 \mathrm{mg}$ per $\mathrm{kg}$ body weight) immediately after insertion of the arterial sheet. Intraarterial blood pressure and electrocardiogram were continuously monitored during PCI. Intracoronary injections of nitrate were given to all patients before stenting and before measurement of CFR and FFR. None of the patients were treated with glycoprotein receptor blocker or bivalirudin.

\section{CFR and FFR measurements}

At the end of the PCI procedure, a 0.014-inch fiberoptic pressure-temperature sensor-tipped guide wire (Pressure Wire Sensor 5; Radi Medical Systems, Uppsala, Sweden) was initially held in the proximal part of the target vessel for equalizing of the pressure between coronary artery and intraaortic pressure, and then advanced through the guiding catheter and positioned distal to the PCI-treated segment for simultaneous measurements of CFR and FFR, respectively. Besides a pressure sensor, this wire has a microsensor at $3 \mathrm{~cm}$ from the floppy tip, which enables simultaneous recording of high fidelity temperature with an accuracy of $0.02^{\circ} \mathrm{C}$. The shaft of the wire, acting as an additional electric resistance, can be used as a second thermistor which records the input signal at the coronary ostium of any fluid injection with a temperature different from blood. Intravenous adenosine was used as hyperemic agent. The mean transit time at rest and during hyperemia were recorded after rapid injection of $3 \mathrm{~mL}$ of room temperature saline through the guiding catheter as previously described. ${ }^{16}$ The hyperemic and resting mean transit times were measured three times and averaged. Thermodilution-derived CFR was calculated as the resting mean transit time divided by the hyperemic mean transit time. ${ }^{17}$

\section{Blood analysis}

Venous blood samples were obtained 12-16 hours after PCI for analysis of cardiac enzymes (CK-MB and troponin I). Blood lipids including low-density lipoprotein (LDL) and high-density lipoprotein (HDL), and glycosylated hemoglobin $\left(\mathrm{HbA}_{\mathrm{lc}}\right)$ were assessed at least four weeks prior to PCI according to local laboratory routines.

\section{Statistical analysis}

Data are shown as means \pm standard error (SE). The nonparametric Mann-Whitney test was used to analyze the 
differences between the groups regarding CFR. A two-tailed probability value of $P<0.05$ was considered significant.

\section{Results}

The basal characteristics of the patients are presented in Table 1. There were no significant differences in age, diabetes duration, $\mathrm{HbA}_{1 \mathrm{c}}$, pre-PCI blood pressure or blood lipids between the groups. The PCI procedure was successful in all patients. Drug-eluted stents were used in 10 patients with diabetes and in two nondiabetic controls. Bare metal stents (BMS) were used in remaining patients. There were no angiographic signs of PCI-related complications in the coronary vessels such as dissection or formation of thrombosis with or without peripheral embolization.

Post-PCI CFR was significantly higher in nondiabetic controls as compared to patients with diabetes, while diabetic patients who received placebo (group C) showed significantly lower CFR compared to those who received endothelin blocker (Groups A and B) (Figure 1; Table 2). However, there was a tendency to lower CFR in diabetic patients who received endothelin blocker compared to nondiabetic controls.
Patients who received bosentan showed lower CFR values than those who received BQ123 (Table 2).

Post-PCI FFR were within normal range in all patients indicating successful treatment of the epicardial stenosis, and there were no significant differences in FFR between the groups (Table 2). CK-MB and troponin-I levels were normal in all patients prior to PCI and there were no significant increases post-PCI in any patients. A resting electrocardiogram was obtained in all patients $12-16$ hours post-PCI and did not show any new changes indicative of myocardial ischemia or myocardial infarction following the PCI procedure. Intraarterial systolic blood pressure values were lower post-PCI compared to pre-PCI in most of the patients. Patients in the bosentan group and nondiabetic controls had higher blood pressure pre- and post-PCI compared to the two other groups (Table 2).

\section{Discussion}

Diabetic microangiopathy is characterized by reduced microvascular reactivity and impaired nutritive capillary circulation. ${ }^{18}$ ET-1 through increased endothelial dysfunction

Table I Baseline characteristics of 20 patients, 15 with diabetes and five nondiabetic controls, undergoing coronary stenting. Patients with diabetes were randomized to endothelin blocker or placebo

\begin{tabular}{|c|c|c|c|c|}
\hline & \multicolumn{3}{|l|}{ Groups } & \multirow{2}{*}{$\begin{array}{l}\text { Nondiabetic } \\
\text { Controls }(n=5)\end{array}$} \\
\hline & $A(n=4)$ & $B(n=6)$ & $C(n=5)$ & \\
\hline Age $(y)$ & $69 \pm 9$ & $62 \pm 4$ & $64 \pm 8$ & $62 \pm 6$ \\
\hline Male/Female (n) & $3 / 1$ & $5 / 1$ & $3 / 2$ & $4 / 1$ \\
\hline Diabetes duration (y) & $9 \pm 5$ & $6 \pm 2$ & $6 \pm 3$ & - \\
\hline Smokers (n) & I & 0 & 0 & I \\
\hline $\mathrm{HbA}_{\mathrm{Ic}}(\%)$ & $6.5 \pm 0.6$ & $6.5 \pm 0.2$ & $6.6 \pm 0.3$ & - \\
\hline $\mathrm{CrCl}(\mathrm{mL} / \mathrm{min})$ & $89 \pm 8$ & $91 \pm 7$ & $89 \pm 6$ & $92 \pm 5$ \\
\hline \multicolumn{5}{|l|}{ Blood pressure (mmHg) } \\
\hline Systolic & $|3| \pm 6$ & $120 \pm 7$ & $123 \pm 15$ & $13 \mid \pm 16$ \\
\hline Diastolic & $76 \pm 7$ & $71 \pm 9$ & $71 \pm 11$ & $75 \pm 14$ \\
\hline \multicolumn{5}{|l|}{ Cholesterol (mmol/L) } \\
\hline Total & $4.0 \pm 0.3$ & $4.0 \pm 0.5$ & $3.8 \pm 0.4$ & $3.9 \pm 0.4$ \\
\hline LDL & $2.5 \pm 0.3$ & $2.5 \pm 0.4$ & $2.4 \pm 0.3$ & $2.4 \pm 0.3$ \\
\hline $\mathrm{HDL}$ & $0.9 \pm 0.1$ & $1.0 \pm 0.1$ & $1.0 \pm 0.1$ & $1.2 \pm 0.1$ \\
\hline \multicolumn{5}{|l|}{ Target vessel (n) } \\
\hline LAD & 2 & 3 & 2 & 3 \\
\hline LCX & 2 & I & 2 & I \\
\hline RCA & - & 2 & I & I \\
\hline
\end{tabular}

Notes: Values are means \pm SE. There were no significant differences between the groups regarding age, diabetes duration, systolic and diastolic blood pressure or blood lipids. Group A: patients with diabetes who received bosentan $(n=4)$. Group B: patients with diabetes who received BQI23 $(n=6)$. Group C: Patients with diabetes who received placebo $(n=5)$.

Abbreviations: $\mathrm{HbA}_{\mathrm{lc}}$, glycosylated hemoglobin; $\mathrm{CrCl}$, creatinine clearance; LDL, low-density lipoprotein; $\mathrm{HDL}$, high-density lipoprotein; LAD, left anterior descending artery; LCX, left circumflex artery; RCA, right coronary artery; SE, standard error. 


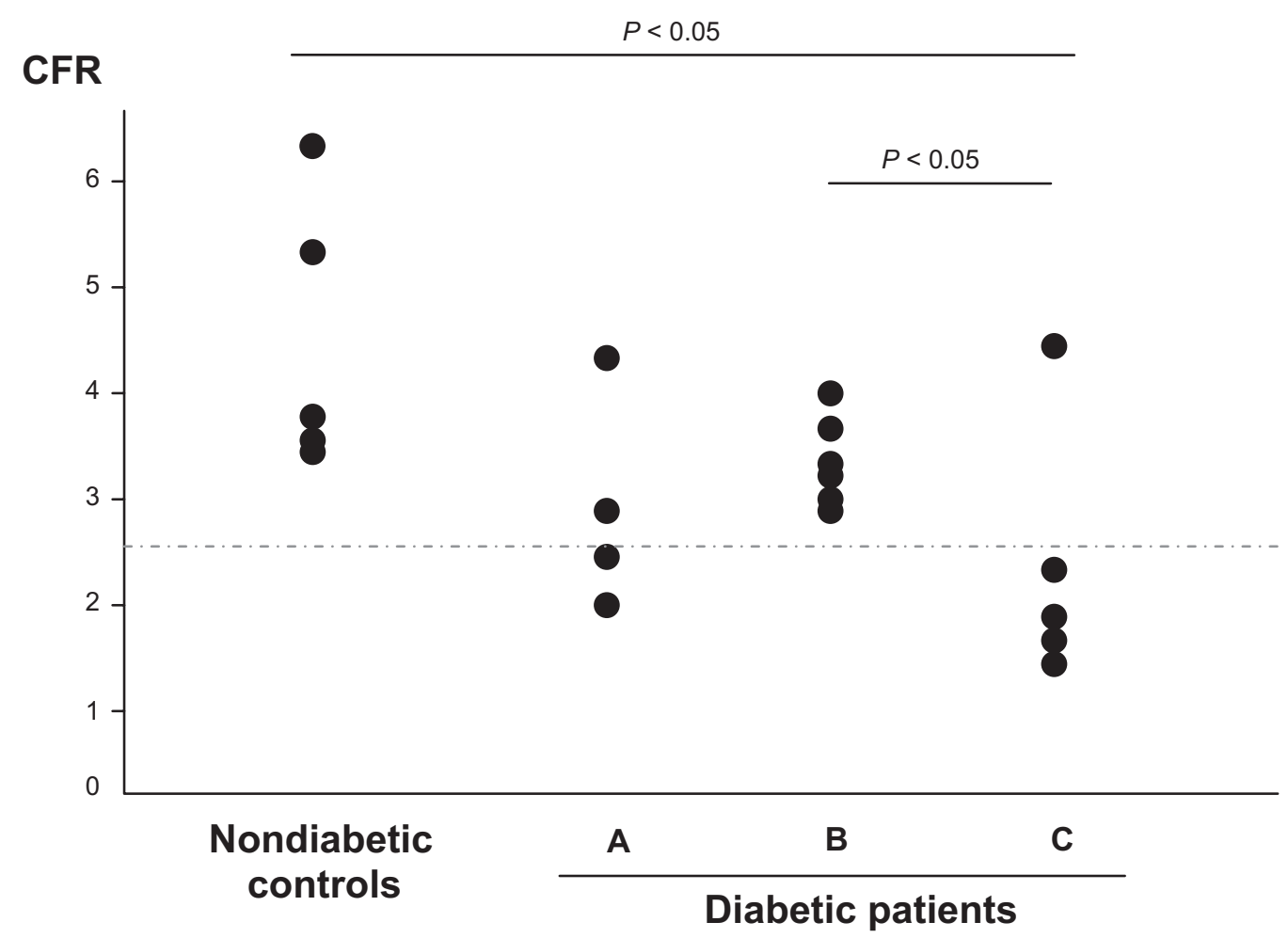

Figure I Coronary flow reserve (CFR) post-coronary stenting in 20 patients; 15 with diabetes and five nondiabetic controls. Patients with diabetes were randomized to bosentan (Group A; $n=4)$, BQI23 (Group B; $n=6$ ) or placebo (Group C; $n=5$ ).

has been suggested to contribute to impaired microvascular reactivity in patients with diabetes. ${ }^{8}$ There is increasing evidence of the presence of disturbed myocardial microvascular function in patients with diabetes and metabolic syndrome. ${ }^{9,10}$ Disturbed microvascular function in the myocardium of patients with diabetes may play an important role in the pathogenesis of systolic and diastolic myocardial dysfunction in absence of epicardial coronary artery disease. As in peripheral microcirculation, an impaired coronary microvascular function is seen during ischemic and/or mechanical stress, eg, PCI, which is suggested to partly explain poor long-term outcome in diabetic patients undergoing coronary revascularization. ${ }^{19}$

The present study was undertaken to explore the hypothesis that in patients with type 2 diabetes, myocardial microvascular function is impaired during percutaneous coronary intervention, and that it can be restored by endothelin-receptor blockade. The results show that coronary microvascular dysfunction is present after PCI with coronary stenting in patients with type 2 diabetes, and that selective $\mathrm{ET}_{\mathrm{A}}$ blockade attenuate microvascular dysfunction in the myocardium.

Table 2 Post-PCl values of CFR, FFR, and intraarterial blood pressure in 15 patients with diabetes and five nondiabetic controls undergoing coronary stenting. Patients with diabetes were randomized to endothelin blocker or placebo

\begin{tabular}{|c|c|c|c|c|}
\hline & \multicolumn{3}{|l|}{ Groups } & \multirow{2}{*}{$\begin{array}{l}\text { Nondiabetic } \\
\text { Controls }(n=5)\end{array}$} \\
\hline & $A(n=4)$ & B $(n=6)$ & $C(n=5)$ & \\
\hline CFR & $2.8 \pm 1.0$ & $3.3 \pm 0.5^{\mathrm{a}}$ & $2.3 \pm 1.2$ & $4.9 \pm 2.3^{b}$ \\
\hline FFR & $0.97 \pm 0.02$ & $0.96 \pm 0.01$ & $0.97 \pm 0.02$ & $0.96 \pm 0.01$ \\
\hline \multicolumn{5}{|c|}{ Blood pressure $(\mathrm{mmHg})$} \\
\hline Systolic & $130 \pm 5$ & $120 \pm 4$ & $122 \pm 14$ & $127 \pm 9$ \\
\hline Diastolic & $76 \pm 6$ & $69 \pm 8$ & $70 \pm 11$ & $70 \pm 9$ \\
\hline
\end{tabular}

Notes: Values are means \pm SE. ${ }^{\mathrm{P}} \mathrm{P}<0.05$ as compared to patients on placebo (Group $\mathrm{C}$ ). ${ }^{\mathrm{b}} \mathrm{P}<0.05$ as compared to patients with diabetes ( $\mathrm{n}=\mathrm{I5}$ ).

Abbreviations: CFR, coronary flow reserve; FFR, fractional flow reserve; PCl, percutaneous coronary intervention; SE, standard error. 
In type 2 diabetes, there is a complex interaction between impaired insulin sensitivity, vascular endothelial dysfunction, and hypertension, which seems to play an important role in the development of functional disturbances in the microcirculation. Impaired insulin sensitivity is associated with a modification of arterial resistance, increased microvascular resistance and macro- and microvascular endothelial dysfunction. ${ }^{20-23}$ ET-1 is one of the most potent vasoconstrictors described and has been suggested to contribute to vascular endothelial dysfunction in diabetes. Elevated levels of ET-1 are found in patients with type 2 diabetes, ${ }^{6,724}$ and ET-1-induced reduction in insulin sensitivity may take part in the development of the metabolic syndrome. ${ }^{25}$ In diabetes mellitus, a primary disturbance in ET-1 production from vascular endothelium exists as an early phenomenon rather than a result of advanced stage of the disease. ${ }^{26,27}$

Furthermore, ET-1 may contribute to the development of endothelial dysfunction, and consequently insulin resistance, by increasing the production of reactive oxygen species, mainly superoxide anion, in the vasculature. ${ }^{28-30}$ Two receptor subtypes, endothelin $\mathrm{A}$ - and $\mathrm{B}$-receptors $\left(\mathrm{ET}_{\mathrm{A}}\right.$ and $\left.\mathrm{ET}_{\mathrm{B}}\right)$, mediate the effects of ET-1. Vascular smooth muscle cells express both $\mathrm{ET}_{\mathrm{A}}$ and $\mathrm{ET}_{\mathrm{B}}$, while endothelial cells express primarily $\mathrm{ET}_{\mathrm{B}}{ }^{31}$ On smooth muscle cells, $\mathrm{ET}_{\mathrm{A}}$ mediates vasoconstriction and mitogenesis, while $\mathrm{ET}_{\mathrm{B}}$ receptor has a dual function and has been shown to cause both vasoconstriction and vasodilation. ${ }^{32,33} \mathrm{ET}_{\mathrm{A}}$ receptor activation contributes to coronary constrictor tone and peripheral and coronary endothelial dysfunction. ${ }^{4,5}$

In patients with acute myocardial infarction, microvascular function in the myocardium measured by CFR is impaired due to several complex factors such as distal embolization, activation of vasoactive peptides, eg, ET-1, and reperfusion injury through several plausible pathways, eg, protein kinase $\mathrm{C}$ activation. Assessment of post-reperfusion CFR in patients with acute myocardial infarction seems to predict left ventricle function recovery and future short-term cardiac events. ${ }^{34-37}$ Patient with diabetes have poor long term outcome after coronary artery stenting partly because of being more prone to distal embolization and exaggerated myocardial microvascular dysfunction during PCI. ${ }^{20,38}$ In the study by Kini and colleagues, patients with diabetes showed significantly lower CFR after PCI as compared to nondiabetic patients despite treatment with the glycoprotein receptor inhibitor abciximab suggesting more pronounced microvascular dysfunction in patients with diabetes. ${ }^{19,20}$ In the present study, impaired CFR post-PCI was partly reversed by intracoronary injection of selective ETA blocker BQ123 in patients with diabetes. However, CFR remained lower in patients with diabetes as compared to nondiabetic patients despite dual and selective endothelin receptor blockade, respectively. These results indicate that beside ET-1, other neurohumoral and/or inflammatory mechanisms may be involved in the pathogenesis of microvascular dysfunction during coronary stenting in diabetic patients.

CFR was somehow lower in bosentan group as compared to BQ123 group, and only slightly higher compared to patients in placebo group. The difference in efficacy between dual and selective endothelin receptor blockade with regard to reversal of myocardial microvascular dysfunction may be due to the different action of $\mathrm{ET}_{\mathrm{A}}$ and $\mathrm{ET}_{\mathrm{B}}$ receptors in various vascular beds. ${ }^{5,39}$ In the study by Halcox and colleagues, bosentan, in opposite to BQ123, did not produce microvascular coronary vasodilation despite epicardial vasodilation. A significant effect of $500 \mathrm{mg}$ bosentan on peripheral vascular endothelial function has been demonstrated in previous studies, ${ }^{15}$ however, a low local myocardial concentration of the drug may also partly explain why bosentan did not produce the same response as intracoronary injected BQ123.

Coronary flow reserve is impaired in arterial hypertension ${ }^{40,41}$ and independently associated with myocardial diastolic function, seen early in diabetic patients. ${ }^{42}$ Blood pressure prior to $\mathrm{PCI}$ was well controlled in all patients prior to PCI, however, intraarterial measured systolic and diastolic blood pressures at baseline was higher in nondiabetic controls and patients in BQ123 group, and remained higher in these two groups at the end of PCI procedure. Despite higher blood pressure, CFR was higher in patients receiving BQ123, indicating a positive effect of selective $\mathrm{ET}_{\mathrm{A}}$ blockade on myocardial microcirculation.

There are limitations with the present study. Small numbers of patients are included in each group in this pilot-study. However, a significant effect on CFR seems to have been produced by intracoronary BQ123 in such a limited study population indicating that ET-1 through $\mathrm{ET}_{\mathrm{A}}$ activation is important in regulation of myocardial microcirculation in diabetic patients. Another limitation is that serum ET-1 levels were not analyzed. However, serum levels of ET-1 are not a reliable measure of its biological activity in the vasculature, or expression of ET-1 receptors. Finally, there is no matched placebo group against BQ123 group, but the probability that intermittent intracoronary injection with physiological saline of a total volume of $9 \mathrm{~mL}$ would influence CFR is low.

In conclusion, the results of the present study show that selective $\mathrm{ET}_{\mathrm{A}}$ receptor blockade attenuates coronary 
microvascular dysfunction after coronary stenting in patients with type 2 diabetes. The results need to be confirmed in a larger double-blind placebo-controlled study.

\section{Disclosures}

The authors report no conflicts of interest in this work.

\section{References}

1. Creager MA, Luscher TF, Cosentino F, et al. Diabetes and vascular disease: pathophysiology, clinical consequences, and medical therapy: Part I. Circulation. 2003;108:1527-1532.

2. Luscher TF, Creager MA, Beckman JA, et al. Diabetes and vascular disease: pathophysiology, clinical consequences, and medical therapy: Part II. Circulation. 2003;108:1655-1661.

3. Kalani M. The importance of endothelin-1 for microvascular dysfunction in diabetes. Vasc Health Risk Manag. 2008;4:1061-1068.

4. Kyriakides ZS, Kremastinos DT, Bofilis E, et al. Endogenous endothelin maintains coronary artery tone by endothelin type A receptor stimulation in patients undergoing coronary arteriography. Heart. 2000;84: 176-182.

5. Halcox JP, Nour KR, Zalos G, et al. Coronary vasodilation and improvement in endothelial dysfunction with endothelin ET(A) receptor blockade. Circ Res. 2001;89:969-976.

6. Takahashi K, Ghatei MA, Lam HC, et al. Elevated plasma endothelin in patients with diabetes mellitus. Diabetologia. 1990;33: 306-310.

7. Mather KJ, Mirzamohammadi B, Lteif A, et al. Endothelin contributes to basal vascular tone and endothelial dysfunction in human obesity and type 2 diabetes. Diabetes. 2002;51:3517-3523.

8. Settergren M, Pernow J, Brismar K, et al. Endothelin-A receptor blockade improves nutritive skin capillary circulation in patients with type 2 diabetes and albuminuria. J Vasc Res. 2008;45:295-302.

9. Pirat B, Bozbas H, Simsek V, et al. Impaired coronary flow reserve in patients with metabolic syndrome. Atherosclerosis. 2008;201: 112-116.

10. Yonaha O, Matsubara T, Naruse K, et al. Effects of reduced coronary flow reserve on left ventricular function in type 2 diabetes. Diabetes Res Clin Pract. 2008;82:98-103.

11. Inoue T, Sakai Y, Morooka S, et al. Expression of polymorphonuclear leukocyte adhesion molecules and its clinical significance in patients treated with percutaneous transluminal coronary angioplasty. $\mathrm{J} \mathrm{Am} \mathrm{Coll}$ Cardiol. 1996;28:1127-1133.

12. el-Tamimi H, Davies GJ, Crea F, et al. Response of human coronary arteries to acetylcholine after injury by coronary angioplasty. $\mathrm{J} \mathrm{Am}$ Coll Cardiol. 1993;21:1152-1157.

13. Caramori PR, Lima VC, Seidelin PH, et al. Long-term endothelial dysfunction after coronary artery stenting. J Am Coll Cardiol. 1999;34:1675-1679.

14. Kalani M, Pernow J, Bragd J, et al. Improved peripheral perfusion during endothelin - a receptor blockade in patients with type 2 diabetes and critical limb ischemia. Diabetes Care. 2008;31:e56.

15. Böhm F, Settergren M, Gonon AT, et al. The endothelin-1 receptor antagonist bosentan protects against ischaemia/reperfusion-induced endothelial dysfunction in humans. Clin Sci (Lond). 2005;108: 357-363.

16. De Bruyne B, Pijls NH, Smith L, et al. Coronary thermodilution ta asssess flow reserve. Experimental validation. Circulation. 2001;104:2003-2006.

17. Pijls NHJ, De Bruyne B, Smith L, et al. Coronary thermodilution to assess flow reserve: Validation in humans. Circulation. 2002;105: 2480-2484.

18. Tooke JE. Possible pathophysiological mechanisms for diabetic angiopathy in type 2 diabetes. J Diabetes Complications. 2000;14: $197-200$.
19. Kini AS, Kim MC, Moreno PR, et al. Comparison of coronary flow reserve and fractional flow reserve in patients with versus without diabetes mellitus and having elective percutaneous coronary intervention and abciximab therapy (from the PREDICT Trial). Am J Cardiol. 2008;101:796-800.

20. Rask-Madsen C, King GL. Mechanisms of disease: endothelial dysfunction in insulin resistance and diabetes. Nat Clin Pract Endocrinol Metab. 2007;3:46-56.

21. Shore AC, Jaap AJ, Tooke JE. Capillary pressure in patients with NIDDM. Diabetes. 1994;43:1198-1202.

22. Gall MA, Rossing P, Skott P, et al. Prevalence of micro- and macroalbuminuria, arterial hypertension, retinopathy and large vessel disease in European type 2 (non-insulin-dependent) diabetic patients. Diabetologia. 1991;34:655-661.

23. Jaap AJ, Hammersley MS, Shore AC. Reduced microvascular hyperaemia in subjects at risk of developing type 2 (non-insulin-dependent) diabetes mellitus. Diabetologia. 1994;37:214-216.

24. Verhaar MC, Strachan FE, Newby DE, et al. Endothelin-A receptor antagonist-mediated vasodilatation is attenuated by inhibition of nitric oxide synthesis and by endothelin-B receptor blockade. Circulation. 1998;97:752-756.

25. Ahlborg G, Lindström J. Insulin sensitivity and big ET-1 conversion to ET-1 after $\mathrm{ET}_{\mathrm{A}}$ - or $\mathrm{ET}_{\mathrm{B}}$-receptor blockade in humans. J Appl Physiol. 2002;93:2112-2121.

26. Donatelli M, Colletti I, Bucalo ML, et al. Plasma endothelin levels in NIDDM patients with macroangiopathy. Diabetes Res. 1994;25: 159-164.

27. Anfossi G, Russo I, Doronzo G, et al. Relevance of the vascular effects of insulin in the rationale of its therapeutical use. Cardiovasc Hematol Disord Drug Targets. 2007;7:228-249.

28. Wedgwood S, McMullan DM, Bekker JM, et al. Role for endothelin-1-induced superoxide and peroxynitrite production in rebound pulmonary hypertension associated with inhaled nitric oxide therapy. Circ Res. 2001;17;89:357-364.

29. Li L, Fink GD, Watts SW, et al. Endothelin-1 increases vascular superoxide via endothelin(A)-NADPH oxidase pathway in low-renin hypertension. Circulation. 2003;25;(107):1053-1058.

30. Romero M, Jiménez R, Sánchez M, et al. Quercetin inhibits vascular superoxide production induced by endothelin-1: Role of NADPH oxidase, uncoupled eNOS and PKC. Atherosclerosis. 2009;202:58-67.

31. Molenaar P, O'Reilly G, Sharkey A, et al. Characterization and localization of endothelin receptor subtypes in the human atrioventricular conducting system and myocardium. Circ Res. 1993;72:526-538.

32. Sakurai T, Yanagisawa M, Masaki T. Molecular characterization of endothelin receptors. Trends Pharmacol Sci. 1992;13:103-108.

33. Seo B, Oemar BS, Siebenmann R, et al. Both ETA and ETB receptors mediate contraction to endothelin-1 in human blood vessels. Circulation. 1994;89:1203-1208.

34. Ikeno F, Inagaki K, Rezaee M, et al. Impaired perfusion after myocardial infarction is due to reperfusion-induced deltaPKC-mediated myocardial damage. Cardiovasc Res. 2007;73:699-709.

35. Meimoun P, Malaquin D, Benali T, et al. Non-invasive coronary flow reserve after successful primary angioplasty for acute anterior myocardial infarction is an independent predictor of left ventricular recovery and in-hospital cardiac events. J Am Soc Echocardiogr. 2009;22:1071-1079.

36. Kitabata $\mathrm{H}$, Imanishi $\mathrm{T}$, Kubo $\mathrm{T}$, et al. Coronary microvascular resistance index immediately after primary percutaneous coronary intervention as a predictor of the transmural extent of infarction in patients with ST-segment elevation anterior acute myocardial infarction. JACC Cardiovasc Imaging. 2009;2:263-272.

37. Albertal M, Voskuil M, Piek JJ, et al. Coronary flow velocity reserve after percutaneous interventions is predictive of periprocedural outcome. Circulation. 2002;105:1573-1578.

38. Herrmann J, Haude M, Lerman A, et al. Abnormal coronary flow velocity reserve after coronary intervention is associated with cardiac marker elevation. Circulation. 2001;103:2339-2345. 
39. Halcox JP, Nour KR, Zalos G, Quyyumi AA. Endogenous endothelin in human coronary vascular function: Differential contribution of endothelin receptor types A and B. Hypertension. 2007;49:1134-1141.

40. Galderisi M, de Simone G, D'Errico A, et al. Independent association of coronary flow reserve with left ventricular relaxation and filling pressure in arterial hypertension. Am J Hypertens. 2008;21: 1040-1046.
41. Galderisi M, Cicala S, Caso P, et al. Coronary flow reserve and myocardial diastolic dysfunction in arterial hypertension. Am J Cardiol. 2002;90:860-864.

42. Jarnert C, Landstedt-Hallin L, Malmberg K, et al. A randomized trial of the impact of strict glycaemic control on myocardial diastolic function and perfusion reserve: a report from the DADD (Diabetes mellitus And Diastolic Dysfunction) study. Eur J Heart Fail. 2009;11:39-47.

\section{Publish your work in this journal}

Vascular Health and Risk Management is an international, peerreviewed journal of therapeutics and risk management, focusing on concise rapid reporting of clinical studies on the processes involved in the maintenance of vascular health; the monitoring, prevention and treatment of vascular disease and its sequelae; and the involvement of metabolic disorders, particularly diabetes. This journal is indexed on PubMed Central and MedLine. The manuscript management system is completely online and includes a very quick and fair peer-review system, which is all easy to use. Visit http://www.dovepress.com/ testimonials.php to read real quotes from published authors.

Submit your manuscript here: http://www.dovepress.com/vascular-health-and-risk-management-journal 